\title{
Changes in self-reported pre- to postinjury coping styles in the first 3 years after traumatic brain injury and the effects on psychosocial and emotional functioning and quality of life
}

Citation for published version (APA):

Wolters Gregorio, G., Gould, K. R., Spitz, G., van Heugten, C. M., \& Ponsford, J. L. (2014). Changes in self-reported pre- to postinjury coping styles in the first 3 years after traumatic brain injury and the effects on psychosocial and emotional functioning and quality of life. Journal of Head Trauma Rehabilitation, 29(3), E43-E53. https://doi.org/10.1097/HTR.0b013e318292fb00

Document status and date:

Published: 07/03/2014

DOI:

10.1097/HTR.0b013e318292fb00

Document Version:

Publisher's PDF, also known as Version of record

Document license:

Taverne

Please check the document version of this publication:

- A submitted manuscript is the version of the article upon submission and before peer-review. There can be important differences between the submitted version and the official published version of record. People interested in the research are advised to contact the author for the final version of the publication, or visit the DOI to the publisher's website.

- The final author version and the galley proof are versions of the publication after peer review.

- The final published version features the final layout of the paper including the volume, issue and page numbers.

Link to publication

\footnotetext{
General rights rights.

- You may freely distribute the URL identifying the publication in the public portal. please follow below link for the End User Agreement:

www.umlib.nl/taverne-license

Take down policy

If you believe that this document breaches copyright please contact us at:

repository@maastrichtuniversity.nl

providing details and we will investigate your claim.
}

Copyright and moral rights for the publications made accessible in the public portal are retained by the authors and/or other copyright owners and it is a condition of accessing publications that users recognise and abide by the legal requirements associated with these

- Users may download and print one copy of any publication from the public portal for the purpose of private study or research.

- You may not further distribute the material or use it for any profit-making activity or commercial gain

If the publication is distributed under the terms of Article 25fa of the Dutch Copyright Act, indicated by the "Taverne" license above, 


\title{
Changes in Self-Reported Pre- to
}

Postinjury Coping Styles in the First

3 Years After Traumatic Brain Injury and the Effects on Psychosocial and Emotional Functioning and Quality of Life

\author{
Gisela Wolters Gregório, PhD; Kate R. Gould, DPsych; Gershon Spitz, BA (Hons); \\ Caroline M. van Heugten, PhD; Jennie L. Ponsford, PhD
}

\begin{abstract}
Objective: To examine the influence of self-reported preinjury coping on postinjury coping, psychosocial functioning, emotional functioning, and quality of life at 1 year following traumatic brain injury (TBI). Setting: Inpatient hospital and community. Participants: One hundred seventy-four participants with TBI. Design: Prospective, longitudinal design. Participants were assessed at 5 time points: after emerging from posttraumatic amnesia, and at 6, 12, 24, and 36 months postinjury. Main Measures: Coping Scale for Adults-Short Version; Quality of Life Inventory; Sydney Psychosocial Reintegration Scale; Hospital Anxiety and Depression Scale. Results: High preinjury use of nonproductive coping style predicted high use of nonproductive coping, more anxiety, and lower psychosocial functioning at 1 year postinjury. Increased use of nonproductive coping and decreased use of productive coping predicted poorer psychosocial outcome at 1 year post-TBI. Use of both productive and nonproductive coping decreased in the first 6 to 12 months post-TBI relative to preinjury. Unlike productive coping, nonproductive coping reached preinjury levels within 3 years postinjury. Conclusion: The findings support identification of individuals at risk of relying on nonproductive coping and poorer psychosocial outcome following TBI. In addition, the results emphasize the need to implement timely interventions to facilitate productive coping and reduce the use of nonproductive coping in order to maximize favorable long-term psychosocial outcome. Key words: adaptation, anxiety, depression, psychological, quality of life, TBI
\end{abstract}

$\mathrm{T}$ RAUMATIC BRAIN INJURY (TBI) is a major cause of disability, with an estimated 5480 new cases of moderate to severe TBI in Australia in 2008.

Author Affiliations: Department of Psychiatry and Neuropsychology, Faculty of Health, Medicine, and Life Sciences, Maastricht University, Maastricht, the Netherlands (Drs Wolters Gregório and van Heugten); Monash-Epworth Rehabilitation Research Centre, Epworth Hospital, Richmond, Victoria, Australia (Drs Gould and Ponsford and Mr Spitz); School of Psychology and Psychiatry, Faculty of Medicine, Nursing, and Health Science, Monash University, Clayton, Victoria, Australia (Drs Gould and Ponsford and Mr Spitz); and Centre of Excellence in Traumatic Brain Injury Research, National Trauma Research Institute, Alfred Hospital, Melbourne, Australia (Drs Gould and Ponsford).

The authors declare no conflicts of interest.

Corresponding Author: Jennie L. Ponsford, PhD, School of Psychology and Psychiatry, Monash University, Clayton Campus, Clayton, VIC 3800, Australia(Jennie.Ponsford@monash.edu).

DOI: 10.1097/HTR.0b013e318292fb00
Lifetime costs are estimated to be $\$ 2.5$ million to $\$ 4.8$ million per survivor, including costs related to reduced quality of life, treatment, and productivity loss. ${ }^{1}$ Being male and younger than 40 years are risk factors for TBI, whereas motor vehicle accidents are the most common causes. ${ }^{2-4}$ The consequences for TBI survivors are often debilitating; studies have reported long-term changes in occupational activities, interpersonal relationships, independent living, and an increased prevalence of psychiatric disorders. ${ }^{5,6}$ Recent research has sought to identify determinants of recovery and functioning after TBI in order to predict and possibly improve outcomes. There is increasing evidence that functioning after TBI is influenced by the way survivors cope with stressful situations. ${ }^{7,8}$

Coping has been defined as the ways individuals deal with situations that are appraised as stressful. ${ }^{9}$ 
Nonproductive or emotion-focused coping styles, characterized by passive reactions and avoidance strategies, are focused on regulating the emotional reaction to the stressor rather than solving the problem. These coping styles have generally been associated with negative outcomes such as poor quality of life, ${ }^{10}$ depression, and anxiety following injury. ${ }^{11,12}$ However, inconsistent findings have been reported regarding the effect of productive or problem-focused coping styles-characterized by actively managing problems-on outcome following injury. Studies have demonstrated positive associations between problem-focused strategies and both self-esteem and generic quality of life. However, problem-focused coping has shown no significant association with anxiety, depression, trait anger, psychosocial dysfunction, subjective complaints, or disease-specific quality of life. ${ }^{10,13,14}$ This suggests that the relation between coping style and outcome is complex. There might be an interaction between an individual's subjective beliefs about the injury (eg, about its controllability or perceived duration) and level of awareness of difficulties. ${ }^{15}$ Further, cognitive difficulties may influence the successful application of a coping strategy. Patients with executive problems may have greater difficulty implementing productive coping strategies and may rely on avoidance strategies, which are considered maladaptive. ${ }^{11,14,16}$ Alternatively, coping resources (eg, individual differences in optimism, mastery, self-esteem, and social support) as well as the evaluation of coping resources (ie, either a negative or positive evaluation to cope with the TBI) have been suggested to moderate the association between stress and coping. ${ }^{17,18}$ Riley et al, for example, ${ }^{17}$ showed that patients low in self-esteem who negatively evaluated their coping resources were more likely to use avoidance when confronted with a potential threat than patients high in self-esteem and those who positively evaluated their coping resources.

Persons with a history of substance use or psychiatric disorders have a higher risk of sustaining TBI, ${ }^{5}$ with both of these associated with worse long-term outcome following injury. ${ }^{19}$ Although it has been suggested that these premorbid factors might represent a limited coping repertoire, ${ }^{19}$ the influence of preinjury coping style on long-term outcome after TBI has rarely been investigated. To our knowledge, the only study that has investigated this influence found greater use of nonproductive coping (ie, emotional preoccupation) at 6 months postinjury than preinjury levels. ${ }^{20}$ The increase in nonproductive coping accounted for significant variance in productivity levels such as traveling, working, and studying. In that study, reports of close others were used to assess patients' coping styles. These reports could only have been based on observable behavior of the injured survivor with potentially inaccurate reports of cognitive, internal coping mechanisms such as development of a plan for action or worrying. The reports may have been influenced by the amount of contact the close other had with the survivor and by their own emotional state. Patients' self-reports obtained soon after injury potentially offer a more accurate means of assessing internal coping mechanisms. While memory or awareness problems may influence ratings of current behavior, this is arguably less of a problem with respect to preinjury behavior, although the potential to idealize the preinjury self must be acknowledged. ${ }^{21}$ At present, no single assessment method has established validity over the others. ${ }^{21}$ The changes in coping from preinjury to the postacute stage following TBI might be due to injury-related neurological and cognitive functioning. Although most changes in functioning are found within the first year postinjury, recovery might still occur as late as 2,5 , or 10 years postinjury. ${ }^{4,22-24}$

Despite evidence of continuing improvements over longer periods postinjury, no studies have investigated changes from preinjury coping to postinjury coping in the chronic phase after TBI. The studies that have investigated changes in coping in patients with TBI focused only on changes in postinjury coping. The use of nonproductive coping strategies increased over time, and the use of productive coping styles either decreased or no changes were observed. ${ }^{10,25}$ In addition, these changes have been shown to be maladaptive, with increases in productive coping styles and decreases in nonproductive coping styles in the chronic phase associated with a better quality of life. ${ }^{10} \mathrm{~A}$ potential explanation of these changes is that the cognitive disorders prohibit the use of productive styles, since these largely depend on intact cognitive functioning (eg, collecting relevant information, making a logical analysis of the situation, understanding the problem correctly $\left.{ }^{26}\right)$. Alternatively, in the chronic phase, patients may realize that the consequences are lasting, and they will never regain their premorbid level of functioning. These increases in awareness may have underpinned the increased use of nonproductive coping strategies, such as avoidance and passive coping. ${ }^{27,28}$

In addition, no studies have investigated the relation between preinjury and postinjury coping. Identifying adaptive or maladaptive coping styles after TBI and their predictors could potentially assist clinicians in the rehabilitation process by identifying at-risk individuals who may need closer monitoring and earlier intervention.

The first aim of this study was to examine the association between self-reported preinjury and postinjury coping. A second aim was to examine whether self-reported preinjury coping, as well as changes in coping following TBI, were associated with psychosocial functioning, depression, anxiety, and quality of life 1 year postinjury. The third aim of the study was to prospectively investigate changes in self-reported coping between preinjury 
and 3 years postinjury. First, we hypothesized that individuals who reported utilizing more nonproductive coping strategies preinjury would show more nonproductive coping 1 year postinjury. Second, we hypothesized that individuals who reported using more preinjury nonproductive coping and who increased their use of nonproductive coping strategies in the first year after TBI would report poorer psychosocial and emotional functioning at 1 year post-TBI. Third, it was hypothesized that the use of nonproductive coping strategies would increase and that the use of productive coping strategies would decrease following TBI.

\section{METHODS}

\section{Participants}

Participants were recruited from consecutive TBI admissions to a rehabilitation hospital between August 2005 and August 2010; 30\% to 50\% of all head injuries in the state of Victoria are treated at this facility. Inclusion criteria were: complicated mild, moderate, or severe TBI; ${ }^{29,30}$ age at injury 16 to 80 years; residence in Australia and availability for follow-up after discharge; and sufficient cognitive and English ability to complete interviews according to the treating neuropsychologist. Participants who sustained a previous TBI or had another neurological disorder (based on self-report and examination of medical files) were excluded.

In total, 174 participants were included in this study. Participants were typically young men with 12 years of education (see Table 1). More than half sustained a TBI as the result of a car accident (53\%), followed by a motorcycle accident (14\%), or were injured as pedestrians $(10 \%)$. Other injuries were sustained because of falls, bicycle, work or sport accidents, as well as assaults and falling from a horse. The injuries ranged from complicated mild to very severe.

\section{Procedure}

Ethics approval was obtained from the relevant hospital and university human research ethics committees. In addition, written consent was obtained from all participants. Injury-related information (ie, Glasgow Coma Scale score, posttraumatic amnesia [PTA] duration) and information about previous health problems was collected from the participant's medical file.

Participants completed semistructured interviews at 5 time points, either face-to-face or by telephone. The initial assessment (T0) was conducted during their inpatient admission following emergence from PTA or soon after discharge, on average, $58.8(\mathrm{SD}=57.2)$ days postinjury. Time between injury and $\mathrm{T} 0$ varied between 11 and 197 days. Follow-up assessments were completed at 6 months (T6), 12 months (T12), 24 months (T24), and 36 months (T36) postinjury (see Table 1). When the T0 interview took place after 3 months postinjury (often because participants had a long PTA duration) the T6 assessment was combined with the initial interview. Thus, after the T0 interview was completed, the researcher administered the T6 interview for the current time period. Therefore, all assessment points other than T0 were fixed. Some patients had received psychological therapy $(14 \%$ at $\mathrm{T} 0,34 \%$ at $\mathrm{T} 6,50 \%$ at $\mathrm{T} 12,56 \%$ at $\mathrm{T} 24,56 \%$ at T36) or medication (24\% at T0, 27\% at T6, $28 \%$ at $\mathrm{T} 12,28 \%$ at $\mathrm{T} 24,41 \%$ at $\mathrm{T} 36)$ since the injury. Demographic information was collected at T0. The use of coping styles was assessed at each time point, with participants retrospectively reporting their preinjury use of coping styles in relation to preinjury concerns at $\mathrm{T} 0$. Measures of quality of life, depression, and anxiety were completed at T0 (reflecting preinjury quality of life and current mood) and T12 (reflecting current quality of life and mood), whereas the measure of psychosocial functioning was only administered at T12. Researchers or psychologists trained in the administration of the interview conducted the assessments.

\section{Measures}

Coping styles were measured at all time points using the Coping Scale for Adults-Short Version (CSA), a 20 -item self-report questionnaire. ${ }^{31}$ Two subscales of the CSA were used in the interviews: dealing with the problem, which is characterized by actively trying to change the situation by using problem-solving or humor (ie, productive coping), and nonproductive coping, which is characterized by using strategies such as self-blame and substance use. The total scores range from 21 to 105 , with higher scores indicating greater use of the coping strategy. These subscales have been strongly related to clinical outcome and have acceptable internal consistency ( $\alpha$ s of .65 and .73, respectively). ${ }^{14,31}$ As the 2 other subscales of the CSA, optimism and sharing, have poor internal consistency ( $\alpha$ s of .45 and .42 , respectively), ${ }^{31}$ they were not administered. In this study, both the productive subscale $(\alpha=.54-.69)$ and the nonproductive subscale $(\alpha=.57-.72)$ had sufficient internal consistency at the different time points.

Quality of life was measured with the Quality of Life Inventory (QOLI), a self-report questionnaire comprising 32 items. A weighted average score is calculated by multiplying importance and satisfaction for each life aspect, and then averaging the scores by dividing the total weighted average score by the number of nonzero-weighted average scores. Range is -6 to $+6 .^{32,33}$ Internal consistency has been reported to be sufficient to high $(\alpha=.77-89)$ across both clinical and nonclinical samples, and validity has been established. ${ }^{33}$

The Hospital Anxiety and Depression Scale (HADS) is a 14-item self-report measure of anxiety and 
TABLE 1 Demographic and injury information

\begin{tabular}{|c|c|c|c|c|c|}
\hline & $n$ & Mean (SD) & Median & Range & Percentage \\
\hline Age at injury, $y$ & 174 & $34.3(16.0)$ & 28 & $16-76$ & \\
\hline Education, y & 174 & $12.0(2.3)$ & 12 & $7-18$ & \\
\hline Gender, male & 174,139 & & & & 80 \\
\hline Time between injury and T0, y & 72 & $0.2(0.1)$ & 0.1 & $0.0-0.5$ & \\
\hline Time between injury and T6, y & 73 & $0.6(0.1)$ & 0.6 & $0.4-0.8$ & \\
\hline Time between injury and T12, y & 99 & $1.1(0.1)$ & 1.1 & $0.8-1.3$ & \\
\hline Time between injury and $T 24, y$ & 109 & $2.2(0.1)$ & 2.1 & $2.0-2.4$ & \\
\hline Time between injury and T36, y & 80 & $3.1(0.1)$ & 3.1 & $3.0-3.6$ & \\
\hline PTA, d & 174 & $20.1(20.0)$ & 15.0 & $0.0-105.0$ & \\
\hline Mild $(<1)$ & 22 & & & & 13 \\
\hline Moderate (1-7) & 37 & & & & 21 \\
\hline Severe (8-28) & 72 & & & & 41 \\
\hline Very severe $(>28)$ & 43 & & & & 25 \\
\hline GCS score & 165 & $9.1(4.3)$ & 9.0 & $3-15$ & \\
\hline Mild (13-15) & 62 & & & & 38 \\
\hline Moderate (9-12) & 43 & & & & 26 \\
\hline Severe (3-8) & 60 & & & & 36 \\
\hline
\end{tabular}

Abbreviations: GCS, Glasgow Coma Scale; PTA, posttraumatic amnesia; SD, standard deviation; T0, initial assessment; T6, T12, T24, T36, assessment at 6-, 12-, 24-, and 36-month postinjury, respectively.

depression symptom severity (HADS-a and HADS-d, respectively). Range is 0 to 42 , with higher scores reflecting greater emotional distress. ${ }^{3,35}$ The HADS-a and HADS-d have high internal consistency ( $\alpha$ s of .83 and .82 , respectively). Validity has been established in both clinical and nonclinical samples. ${ }^{36}$

Psychosocial functioning was assessed using the Sydney Psychosocial Reintegration Scale Form A (SPRS), ${ }^{37}$ which was developed specifically for use in TBI populations. It comprises 12 statements, with 4 items corresponding to the 3 domains of occupational activities, interpersonal relationships, and independent living skills. Ratings of each statement relate to "change because of the injury." The 3 domain scores range from 0 to 24, with higher scores indicating less impairment in psychosocial functioning. The SPRS has high internal consistency $(\alpha=.90)$ and 1 -month stability $(r i=.90) .{ }^{37}$

\section{Statistical analyses}

Associations between preinjury coping and coping at T6, T12, T24, and T36 were examined using Pearson product-moment correlation coefficients $(r)$.

To investigate the influence of preinjury coping style and changes in coping style on psychosocial and emotional functioning and quality of life at T12, 4 hierarchical multiple regression analyses were performed. Preinjury coping styles and changes in coping styles were included as independent variables, with the scores on the QOLI, SPRS, HADS-a, and HADS-d at T12 as the dependent variables. To control for potential covariates, Pearson correlation coefficients were calculated between demographic and injury variables and coping and outcome variables. Education and gender were associated with coping and outcome, respectively, and were therefore also included in the regression analyses to control for their effects. Only patients who completed all questionnaires relevant for the model were analyzed. The assumptions of regression analysis (homoscedasticity, normal distribution of the residuals, and absence of multicollinearity and influential outliers) were fulfilled for each model.

To investigate changes in the use of coping styles from pre- to postinjury and the factors that predicted these changes, multilevel analyses were performed. ${ }^{38}$ Time of assessment and gender were standardized with 0 representing time T0 and male gender respectively. Demographic and injury severity variables were standardized, such that their mean was zero. This allowed the changes in coping over time to be interpreted for male patients with average age, education, and PTA duration. Two "unconditional means" models were initially fitted, with CSA scores as the outcome, but without predictors (model A). This enabled an examination as to whether there was sufficient variation within as well as between individuals that might be explained using additional predictors. Subsequently, logistic regression analyses were performed to investigate which demographic and injury severity variables were related to the failure to complete an assessment. Older age, female gender, low educational attainment, and shorter PTA duration were related to missing assessments at least at one time point. These variables were added to the second models in order to control for the possible influence of these variables on outcome (model B). An "unconditional growth" model was subsequently fitted, which introduced the time 
predictor into the model (model C). After this model was fitted, quadratic and exponential time effects were introduced to the model in order to investigate the presence of nonlinear changes in coping over time (models $\mathrm{D}$ and $\mathrm{E}$, respectively).

Full maximum likelihood was used for parameter estimation. Model fit statistics-including deviance statistic and the Akaike Information Criterion-were used to identify the best model. Significant differences in deviance statistics between 2 models indicated that inclusion of additional parameters resulted in a significantly better model than the previous model.

Power analysis for the multiple regression analyses led to an estimated number of 49 participants required, given $\alpha=.05,7$ predictors in the model, large effect size (ie, Cohen $d=0.80$ ), and power $=0.80 .^{39}$ Statistical analyses were performed using IBM SPSS 20.0 for Mac OS X (New York). P values below .05 were considered statistically significant, except for the exploratory analyses where we considered a $P<.10$ to be significant to limit the probability of making a type II error.

\section{RESULTS}

\section{Association between preinjury and long-term postinjury coping}

Table 2 presents the scores on the CSA at the different measurement points. Examination of the association between preinjury and postinjury coping revealed that high use of nonproductive preinjury coping was significantly associated with high use of postinjury use of nonproductive coping at T12 $(r=0.37, P<.05, n=$ $47)$ and T24 $(r=0.42, P<.05, n=36)$. Preinjury productive coping was associated with productive coping at T6 $(r=0.31, P<.01, n=45)$ and T24 $(r=0.47$, $P<.01, n=36)$, and also with nonproductive coping at T6 $(r=0.35, P<.05, n=45)$. No associations were demonstrated between preinjury coping and coping at T36, but it should be noted that only 20 participants completed both of these assessments.

\section{Outcome at 1 year postinjury}

Quality of life was lower at 1 year postinjury than preinjury $\left(t_{45}=2.34, P<.05\right)$, as measured with the QOLI. Although more than half of the participants reported average or high quality of life at 1 year postinjury ( $45 \%$ and $20 \%$, respectively), $35 \%$ reported dissatisfaction with their lives (score lower than 1.6). ${ }^{32}$ Compared to preinjury status, participants reported greatest psychosocial impairment in occupational activities $(M=17.0, \mathrm{SD}=5.2)$, followed by changes in interpersonal relationships $(M=20.3, \mathrm{SD}=$ 4.2) and independent living skills $(M=21.9, \mathrm{SD}=$ 3.1 ) on the SPRS. The majority of participants had

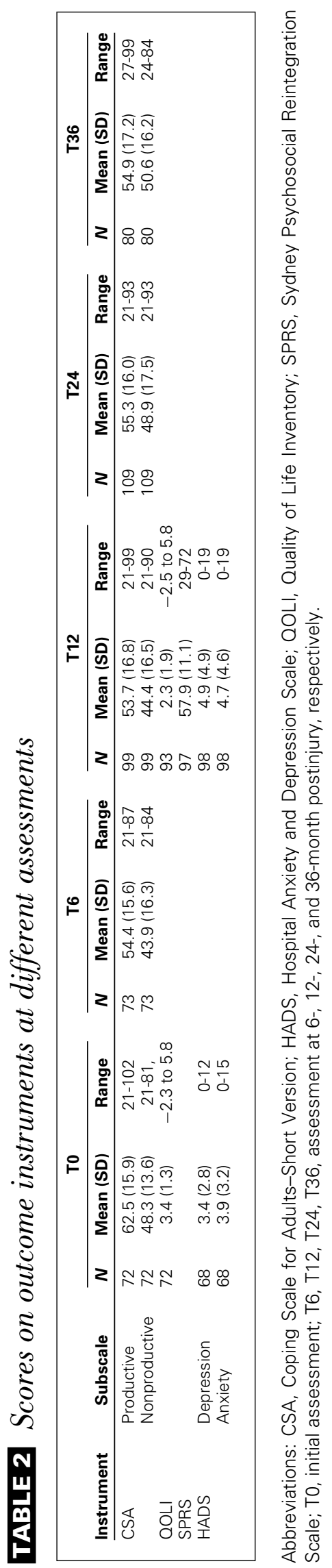

www.headtraumarehab.com 
depression (HADS-d) and anxiety (HADS-a) scores in the normal range at 1 year postinjury $(67 \%$ and $74 \%$ respectively); however, $17 \%$ reported moderate to severe depression symptoms and 15\% reported moderate to severe anxiety symptoms (score higher than 7). At T0, $10 \%$ and $13 \%$ reported moderate to severe depression and anxiety scores, respectively (see Table 2). ${ }^{34}$ The differences in depression and anxiety scores between T0 and 1 year postinjury were not significant $\left(t_{42}=-1.56\right.$, $P>.05 ; t_{42}=.72, P>.05$, respectively).

\section{The influence of preinjury coping and changes in coping on outcome at 1 year postinjury}

Regression analyses showed that preinjury coping scores were significantly predictive of anxiety and psychosocial functioning at T12. Greater use of nonproductive coping preinjury predicted lower psychosocial functioning and increased symptoms of anxiety. In addition, participants who displayed an increase in nonproductive coping, rather than those showing no change or negative change, displayed poorer outcome at T12. That is, these participants showed decreased quality of life, greater depression and anxiety, and lower psychosocial functioning. In comparison, increased use of productive coping styles between $\mathrm{T} 0$ and $\mathrm{T} 12$ predicted better psychosocial functioning at T12. The models explained between $39 \%$ and $65 \%$ of variance (see Table 3 ).

\section{Changes in coping from preinjury to 3 years postinjury}

The growth models (model C) showed a significant decrease in the use of productive coping over time, but nonproductive coping was not linearly associated with time (see Table 4). The nonsignificant rate of change variance components and covariance components of both models indicated that the trajectory of coping scores did not differ significantly between individuals over the first 3 years, nor was the magnitude of coping scores at the initial time point, representing preinjury coping, associated with the rate of coping changes.

To investigate the influence of nonlinear effects of time, we investigated both a quadratic (model D) and an exponential (model E) time effect. Both nonlinear time effects were statistically significant. There were no significant interactions between demographic and injury severity variables with time, indicating that these variables did not predict changes in coping over time. The models with the exponential time effects were superior to the models with linear and quadratic time effects, based on the deviance and Akaike Information Criterion statistics. Model E was consequently the final model.

The final models are depicted in Figure 1. The figure confirms that the use of productive coping styles was more prevalent than nonproductive coping styles both preinjury and at each time postinjury (also suggested in Table 3). The models suggest that use of productive coping styles decreased in the first 6 months postinjury, with a slight increase after 1 year postinjury, but did not reach preinjury levels. Use of nonproductive coping also decreased initially and increased thereafter to the same or higher levels than preinjury levels.

\section{DISCUSSION}

The aims of this study were to investigate the association between pre- and postinjury coping styles after TBI, the influence of coping on outcome at 1 year postinjury, and the changes in coping styles over time after TBI. There were several interesting findings of this study. First, preinjury coping style was positively associated with postinjury coping style. Second, as expected, increases in the use of nonproductive coping and decreases in productive coping predicted worse psychosocial outcome at 1 year postinjury. Moreover, consistent with our expectations, high use of nonproductive coping style preinjury predicted worse outcome. Third, contrary to our expectations, productive coping did not decrease and nonproductive coping did not increase linearly. Both types of coping initially decreased, but nonproductive coping increased at a greater rate following the 1-year time point; there was no concomitant rise in the use of productive strategies.

The finding that preinjury coping was related to postinjury coping was not unexpected. We used the dispositional version of the CSA, which measures coping preferences. This suggests that TBI survivors with a history of using nonproductive coping styles continue to employ these coping styles postinjury. We demonstrated significant effects of preinjury coping on outcome 1 year post-TBI, even after we controlled for postinjury coping. This finding contradicts the only other study that investigated the influence of preinjury coping on outcome. ${ }^{20} \mathrm{~A}$ possible explanation for this discrepancy between studies may be that, unlike Dawson et $\mathrm{al},{ }^{20}$ measures in the current study were administered in the chronic phase after injury; some recovery of cognitive functioning and functional independence is still expected in the chronic phase, ${ }^{22,23}$ as well as increases in emotional distress. ${ }^{40}$ Increased awareness of lasting consequences of the injury, difficulties in performing activities at work or home, decreases in social support, or financial problems could lead to these detrimental changes. ${ }^{40}$ Another explanation is that preinjury coping is less likely to have a direct effect on productivity level, but more likely to be associated with psychosocial and emotional outcomes, such as anxiety and psychosocial functioning. In line with the results of Dawson et $\mathrm{al}^{, 20}$ we did not find an association between preinjury productive coping and outcome. In addition, the negative 


\section{TABLE 3 Linear regression models with outcome measurements at T12 as dependent variables $^{a}$}

\begin{tabular}{|c|c|c|c|c|c|c|}
\hline & B & Standard Error & $\beta$ & $t$ & $P$ & $R^{2}$ \\
\hline \multicolumn{7}{|l|}{ Model 1: OOLI T12 } \\
\hline (Constant) & 27.87 & 18.92 & & 1.47 & .15 & \\
\hline Pre CSA productive & 0.06 & 0.33 & .03 & 0.17 & .86 & \\
\hline Pre CSA nonproductive & -0.33 & 0.29 & -.18 & -1.14 & .26 & \\
\hline C CSA productive & 0.12 & 0.23 & .09 & 0.53 & .60 & \\
\hline C CSA nonproductive & -0.79 & 0.26 & -.51 & $-3.12^{c}$ & .00 & \\
\hline QOLI TO & 0.79 & 0.21 & .59 & $3.74^{c}$ & .00 & \\
\hline Gender & 23.49 & 9.00 & .35 & $2.61^{b}$ & .01 & \\
\hline Education & 0.02 & 1.49 & .00 & 0.01 & .99 & 0.39 \\
\hline \multicolumn{7}{|l|}{ Model 2: HADS-d T12 } \\
\hline Constant & 9.62 & 3.04 & & $3.16^{c}$ & .00 & \\
\hline Pre CSA productive & 0.01 & 0.06 & .03 & 0.18 & .86 & \\
\hline Pre CSA nonproductive & 0.07 & 0.06 & .19 & 1.17 & .25 & \\
\hline C CSA productive & 0.01 & 0.04 & .04 & 0.28 & .78 & \\
\hline C CSA nonproductive & 0.18 & 0.04 & .65 & $4.73^{\mathrm{C}}$ & .00 & \\
\hline HADS-d TO & 0.53 & 0.24 & .31 & $2.18^{\mathrm{b}}$ & .04 & \\
\hline Gender & -3.23 & 1.47 & -.28 & $-2.20^{\mathrm{b}}$ & .03 & \\
\hline Education & -0.29 & 0.24 & -.16 & -1.22 & .23 & 0.51 \\
\hline \multicolumn{7}{|l|}{ Model 3: HADS-a T12 } \\
\hline Constant & 4.82 & 2.38 & & 2.02 & .05 & \\
\hline Pre CSA productive & 0.02 & 0.04 & .08 & 0.56 & .58 & \\
\hline Pre CSA nonproductive & 0.12 & 0.04 & .38 & $2.79^{\mathrm{c}}$ & .01 & \\
\hline C CSA productive & 0.03 & 0.03 & .14 & 1.13 & .27 & \\
\hline C CSA nonproductive & 0.20 & 0.03 & .79 & $6.86^{\mathrm{c}}$ & .00 & \\
\hline HADS-a T0 & 0.37 & 0.16 & .27 & $2.25^{\mathrm{b}}$ & .03 & \\
\hline Gender & -2.87 & 1.11 & -.27 & $-2.58^{b}$ & .01 & \\
\hline Education & 0.10 & 0.19 & .06 & 0.50 & .62 & 0.65 \\
\hline \multicolumn{7}{|l|}{ Model 4: SPRS T12 } \\
\hline Constant & 56.86 & 6.48 & & $8.77^{\circ}$ & .00 & \\
\hline Pre CSA productive & 0.11 & 0.11 & .14 & 0.97 & .34 & \\
\hline Pre CSA nonproductive & -0.24 & 0.10 & -.33 & $-2.44^{b}$ & .02 & \\
\hline C CSA productive & 0.20 & 0.07 & .37 & $2.67^{b}$ & .01 & \\
\hline C CSA nonproductive & -0.40 & 0.08 & -.67 & $-5.16^{c}$ & .00 & \\
\hline Gender & 2.00 & 3.04 & .08 & 0.66 & .51 & \\
\hline Education & 0.22 & 0.51 & .05 & 0.44 & .67 & 0.49 \\
\hline
\end{tabular}

Abbreviations: C, change score; CSA, Coping Scale for Adults-Short Version; pre, preinjury; HADS-d, Hospital Anxiety and Depression Scale-Depression subscale; HADS-a, Hospital Anxiety and Depression Scale-Anxiety subscale; QOLI, Quality of Life; SPRS, Sydney Psychosocial Reintegration Scale; T0, initial assessment; T12, assessment at 12 months postinjury.

a Model $1(n=46)$, model 2 and $3(n=43)$, model $4(n=47)$.

b $P<.05$.

${ }^{\mathrm{c}} P<.01$.

influence of increases in the postinjury use of nonproductive coping and decreases in the use of productive coping on outcome is consistent with previous research showing that increased use of nonproductive coping (ie, emotional preoccupation) was associated with low productivity levels 6 months after TBI. ${ }^{20}$

Previous studies that investigated changes in coping over time have mainly measured coping at 2 time points, ${ }^{10,20,25}$ which limits interpretation of linear relations. Measuring coping at 5 time points allowed for examination of more complex changes. The initial decreases in the use of nonproductive and productive coping styles may have been accompanied by increased use of other coping styles such as seeking social or spiritual support or focusing on the positives, which are captured by the CSA scales not used in this study, due to their low internal consistency. ${ }^{31}$ These strategies may become more important in the initial phases. Another explanation for the initial decreases is that patients with TBI often have limited insight in their problems. Because they experience fewer problems, they will not employ coping strategies. After a while, the support network may decrease and awareness of the lasting consequences of the injury may increase, which may cause the use of nonproductive coping strategies to increase in the post-acute and chronic phases. ${ }^{28}$ The current findings 







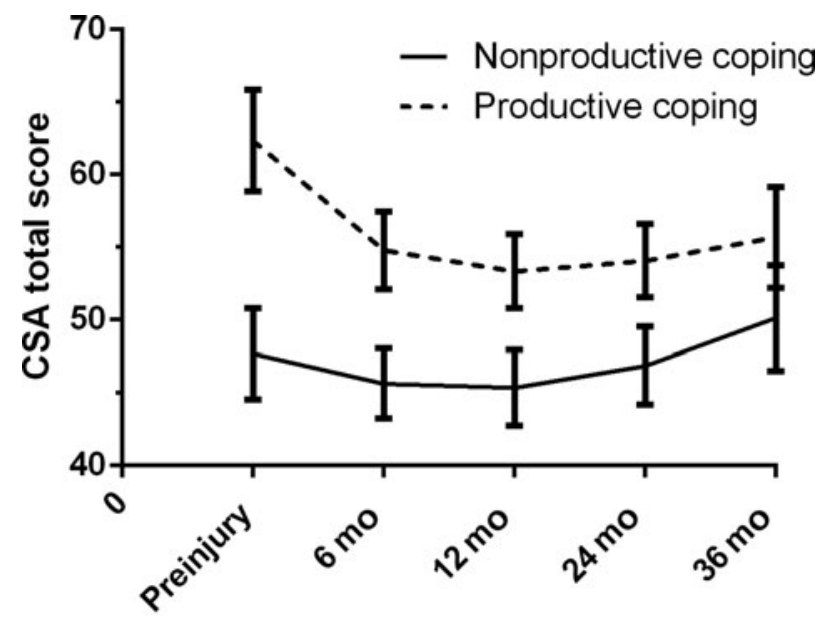

Time

Figure 1. Changes in the use of coping styles after TBI in males with average age, educational attainment, and PTA duration (model E). Error bars represent lower and upper 95\% confidence intervals. Abbreviations: TBI, traumatic brain injury; PTA, posttraumatic amnesia; CSA, Coping Scale for Adults-Short Version.

differ from the course reported by Dawson et a ${ }^{20}$ who showed that preoccupation, an example of nonproductive coping, increased in the first 6 months after TBI. This may be explained by the fact that Dawson et al ${ }^{20}$ used caregiver reports to rate the participants' use of coping styles. We would argue that caregivers may be less accurate in their report of the use of coping styles of their significant other because they can only observe the outcome of the coping process, not the internal states of the other. However, there is still uncertainty as to whose reporting is more accurate, that of close others or that of the individuals with TBI themselves.

\section{Limitations and strengths}

This is one of the few studies that investigated changes in the use of coping styles by individuals with TBI from preinjury to postinjury. Furthermore, we performed a power analysis for the multiple regression analyses investigating the influence of coping on outcome. This analysis showed that we needed 49 participants to find a large effect. We included data of 43 to 47 participants in the analyses, approximating the targeted sample size. In addition, this study is the first that investigated changes in coping over a long time period, that is, over the first 3 years post-TBI. By using longitudinal designs, reliable conclusions about changes over time can be drawn, and by measuring coping at multiple time points, more complex changes can be demonstrated.

A limitation of this study is the presence of missing data at different time points, due to difficulty contacting persons despite multiple efforts. No missing data imputation or replacement was undertaken for the multiple regression analyses, in which we only analyzed complete cases. One advantage of multilevel analysis, however, is that individuals with missing observations are kept in the analysis. This makes the predictions more accurate than when only considering individuals with complete data at all time points. ${ }^{41}$ Variables that were significant predictors for missing data at the different assessments were included as covariates in our models. In addition, we did not control for the influence of psychological treatment patients had received since the injury. These treatments were variable and not focused on coping. Post hoc analyses showed that patients who had received psychological therapy reported more nonproductive coping strategies at T12 and T24 than patients who had not received psychological treatment. It is possible that these associations arose because individuals with more nonproductive coping strategies were more likely to be referred for psychological intervention. However, it would appear that that intervention did not alter their coping style significantly. More research is necessary to investigate the effects of psychological therapy on coping.

A further limitation was that preinjury coping data was gathered retrospectively, which might not provide a fully accurate description of actual premorbid use of coping styles due to the possible influence of injuryrelated cognitive impairments or depressive symptoms, particularly given that the majority of our sample had sustained severe TBI. However, rates of depressive disorders were low and cognitive impairments arguably less likely to affect recall of preinjury behavior than of current behavior. We would argue that the perspective of the injured person is important and that they are still likely to be more accurate raters of their preinjury coping style than their relatives. However, there is a need for further examination of the validity of both methods by including reports by both parties in future studies. Finally, regarding the study measures used, only the SPRS was developed specifically for the TBI population, although the other measures have also been used quite extensively in previous research on persons with TBI.

\section{Implications}

The demonstration of an association between preinjury coping and postinjury coping, suggests that it is possible to predict early after injury who will cope well. Since preinjury nonproductive coping also predicted outcome at 1 year postinjury, we believe it is worth considering preinjury coping styles in initial assessment of individuals as part of the rehabilitation process. This information may be used to guide interventions to improve outcome in the chronic phase. Productive coping may be facilitated in those not exhibiting this coping style. These participants may also benefit from a different rehabilitation approach, since they are accustomed 
to using avoidance, substance use, or passive reactions to deal with problems. If the decreases in productive and nonproductive coping styles in the initial phases are accompanied by increases in other coping styles, such as support seeking and optimism, it is important to facilitate these strategies in later phases as well (eg, facilitate the support network and stimulate optimisticbut also realistic-thoughts). If the decreases in coping strategies represent an overall decrease in strategies, related to limited insight during the initial phases, it is important to train patients in productive coping strate- gies and teach them that nonproductive styles are not adaptive in the long term. This might enable more successful coping with their new problems. In addition, nonproductive coping styles might continue to decrease in the chronic phases after injury, subsequently influencing psychosocial outcome. While the efficacy of these interventions requires further evaluation, we would recommend intervention early postinjury to reduce or prevent the initial decrease in productive coping as well as to prevent greater reliance on nonproductive coping after 6 months.

\section{REFERENCES}

1. Access Economics Pty Limited. The Economic Cost of Spinal Cord Injury and Traumatic Brain Injury in Australia. Geelong, Victoria, Australia: Victorian Neurotrauma Initiative; 2009.

2. Finfer SR, Cohen J. Severe traumatic brain injury. Resuscitation. 2001;48:77-90.

3. Helps Y, Henley G, Harrison JE. Hospital Separations due to Traumatic Brain Injury, Australia 2004-05. Adelaide, South Australia, Australia: AIHW; 2008. Injury Research and Statistics Series No. 45 (Cat No. INJCAT 116).

4. Fleminger S, Ponsford J. Long-term outcome after traumatic brain injury - more attention needs to be paid to neuropsychiatric functioning. BMJ. 2005;331:1419-1420.

5. Gould KR, Ponsford JL, Johnston L, Schonberger M. The nature, frequency and course of psychiatric disorders in the first year after traumatic brain injury: a prospective study. Psychol Med. 2011;41:2099-2109.

6. Temkin NR, Corrigan JD, Dikmen SS, Machamer J. Social functioning after traumatic brain injury. J Head Trauma Rebabil. 2009;24:460-467.

7. Martz E, Livneh H, eds. Coping With Chronic Illness and Disability. Theoretical, Empirical, and Clinical Aspects. New York, NY: Springer; 2007.

8. Tate RL, Broe GA. Psychosocial adjustment after traumatic brain injury: what are the important variables? Psychol Med. 1999;29:713-725.

9. Folkman S, Lazarus RS, Gruen RJ, DeLongis A. Appraisal, coping, health status, and psychological symptoms. J Pers Soc Psychol. 1986;50:571-579.

10. Wolters Gregório G, Stapert S, Brands I, van Heugten C. Coping styles in relation to cognitive rehabilitation and quality of life after brain injury. Neuropsychol Rehabil. 2010;20:587-600.

11. Curran CA, Ponsford JL, Crowe S. Coping strategies and emotional outcome following traumatic brain injury: a comparison with orthopedic patients. J Head Trauma Rebabil. 2000;15:12561274.

12. Gould KR, Ponsford JL, Johnston L, Schönberger M. Predictive and associated factors of psychiatric disorders after traumatic brain injury: a prospective study. J Neurotrauma. 2011;28:11551163.

13. Wolters Gregório G, Stapert S, Brands I, van Heugten C. Coping following acquired brain injury: predictors and correlates. J Head Trauma Rehabil. 2011;26:150-157.

14. Anson K, Ponsford J. Coping and emotional adjustment following traumatic brain injury. J Head Trauma Rehabil. 2006;21:248-259.

15. Medley AR, Powell T, Worthington A, Chohan G, Jones C. Brain injury beliefs, self-awareness, and coping: a preliminary cluster analytic study based within the self-regulatory model. Neuropsychol Rebabil. 2010;20:899-921.
16. Krpan KM, Levine B, Stuss DT, Dawson DR. Executive function and coping at one-year posttraumatic brain injury. J Clin Exp Neuropsychol. 2007;29:36-46.

17. Riley GA, Dennis RK, Powell T. Evaluation of coping resources and self-esteem as moderators of the relationship between threat appraisals and avoidance of activities after traumatic brain injury. Neuropsychol Rehabil. 2010;20:869-882.

18. Taylor SE, Stanton AL. Coping resources, coping processes, and mental health. Annu Rev Clin Psychol. 2007;3:377-401.

19. MacMillan PJ, Hart RP, Martelli MF, Zasler ND. Preinjury status and adaptation following traumatic brain injury. Brain Inj. 2002;16:41-49.

20. Dawson DR, Catanzaro AM, Firestone J, Schwartz M, Stuss DT. Changes in coping style following traumatic brain injury and their relationship to productivity status. Brain Cogn. 2006;60:214-216.

21. Krpan KM, Stuss DT, Anderson ND. Planful versus avoidant coping: behavior of individuals with moderate-to-severe traumatic brain injury during a psychosocial stress test. J Int Neuropsychol Soc. 2011;17:248-255.

22. Hammond FM, Grattan KD, Sasser H, Corrigan JD, Bushnik T, Zafonte RD. Long-term recovery course after traumatic brain injury: a comparison of the functional independence measure and disability rating scale. J Head Trauma Rehabil. 2001;16:318-329.

23. Christensen BK, Colella B, Inness E, et al. Recovery of cognitive function after traumatic brain injury: a multilevel modeling analysis of Canadian outcomes. Arch Phys Med Rehabil. 2008;89:S3-15.

24. Sbordone RJ, Liter JC, Pettler-Jennings P. Recovery of function following severe traumatic brain injury: a retrospective 10-year follow-up. Brain Inj. 1995;9:285-299.

25. Tomberg T, Toomela A, Ennok M, Tikk A. Changes in coping strategies, social support, optimism and health-related quality of life following traumatic brain injury: a longitudinal study. Brain Inj. 2007;21:479-488.

26. Moore AD, Stambrook M. Cognitive moderators of outcome following traumatic brain injury: a conceptual model and implications for rehabilitation. Brain Inj. 1995;9:109-130.

27. Kendall E, Terry DJ. Psychosocial adjustment following closed head injury: a model for understanding individual differences and predicting outcome. Neuropsychol Rehabil. 1996;6:101-132.

28. Ownsworth T, McFarland K. Investigation of psychological and neuropsychological factors associated with clinical outcome following a group rehabilitation programme. Neuropsychol Rehabil. 2004;14:535-562.

29. Williams DH, Levin HS, Eisenberg HM. Mild head injury classification. Neurosurgery. 1990;27:422-428.

30. Kashluba S, Hanks RA, Casey JE, Millis SR. Neuropsychologic and functional outcome after complicated mild traumatic brain injury. Arch Phys Med Rehabil. 2008;89:904-911. 
31. Frydenberg E, Lewis R. Coping Scale for Adults. Melbourne, Victoria, Australia: The Australian Council for Educational Research; 1997.

32. Frisch M. Quality of Life Inventory. Minneapolis, MN: BCDE; 1994.

33. Frisch MB, Cornell J, Villanueva M, Retzlaff PJ. Clinical validation of the Quality of Life Inventory. a measure of life satisfaction for use in treatment planning and outcome assessment. Psychol Assess. 1992;4:92-101.

34. Snaith RP, Zigmond AS. HADS: Hospital Anxiety and Depression Scale. Windsor, England: National Foundation for Educational Research Nelson; 1994.

35. Zigmond AS, Snaith RP. The hospital anxiety and depression scale. Acta Psychiatr Scand. 1983;67:361-370.

36. Bjelland I, Dahl AA, Haug TT, Neckelmann D. The validity of the Hospital Anxiety and Depression Scale. an updated literature review. J Psychosom Res. 2002;52:69-77.
37. Tate R, Hodgkinson A, Veerabangsa A, Maggiotto S. Measuring psychosocial recovery after traumatic brain injury: psychometric properties of a new scale. J Head Trauma Rehabil. 1999;14:543557.

38. Singer JD, Willett JB. Applied Longitudinal Data Analysis: Modelling Change and Event Occurence. New York, NY: Oxford University Press; 2003.

39. Erdfelder E, Faul F, Buchner A. GPOWER: a general power analysis program. Bebav Res Methods Instrum Comput. 1996;28:1-11.

40. Backhaus SL, Ibarra SL, Klyce D, Trexler LE, Malec JF. Brain injury coping skills group: a preventative intervention for patients with brain injury and their caregivers. Arch Phys Med Rehabil. 2010;91:840-848.

41. Tan FES. Best practices in analysis of longitudinal data: a multilevel approach. In: Osborne JW, ed. Best Practices in Quantitative Methods. Los Angeles, CA: Sage; 2008:451-471, chap 30. 